REVIEW ARTICLE

\title{
Challenges for Measuring Progress towards the Sustainable Development Goals
}

\author{
Lindsay Edouard ${ }^{1}$ and Stan Bernstein ${ }^{2}$ \\ Women Wellbeing Unlimited, Blue Bay, Mauritius ${ }^{1}$; ReGeneration Consulting LLC, New York, USA ${ }^{2}$
}

*For correspondence: Email: soranae@gmail.com; Phone: +(230) 212-1980

\begin{abstract}
With the adoption, in September 2015, of the Sustainable Development Goals with a time horizon of 2030, there is a dire need to exploit avenues for the monitoring of progress towards meeting the targets pertaining to sexual and reproductive health, whether at global, regional, national or grassroots level. The current process for the selection of indicators, to complement the targets, provides an opportunity for a concerted effort to improve monitoring procedures and ensure their relevance for programme adjustment and accountability. It is imperative for national processes to ensure effective reporting besides linkages with related sectors. (Afr J Reprod Health 2016 (Special Edition); 20[3]: 45-54).
\end{abstract}

Keywords: Indicators; International development; Social sector; Global health; Gender

\section{Résumé}

Avec l'adoption, en septembre 2015, des Objectifs de développement durable avec un horizon de 2030, il y a un besoin urgent d'exploiter des pistes pour le suivi des progrès en vue d'atteindre les objectifs relatifs à la santé sexuelle et de la reproduction, que ce soit au niveau mondial, régional, national ou local. Le processus actuel de sélection des indicateurs, afin de compléter les objectifs, offre l'occasion d'un effort concerté pour améliorer les procédures de suivi et d'assurer leur pertinence pour l'ajustement du programme et la reddition de comptes. Il est impératif pour les processus nationaux pour assurer des rapports efficaces en plus des liens avec les secteurs connexes. (Afr J Reprod Health 2016 (Edition Spéciale); 20[3]: 45-54).

Mots-clés: indicateurs, développement international, secteur social, santé mondiale, genre

\section{Introduction}

\section{Changing perspectives}

Until last year, the Millennium Declaration guided activities in international development for achieving the eight Millennium Development Goals (MDGs) with their 21 targets and related 60 indicators ${ }^{1,2}$. From the vantage point of reproductive health, "the adoption of the Sustainable Development Goals (SDGs) ${ }^{3 \text { " }}$ at the United Nations Summit in September 2015 should be viewed in the historical context of the longstanding role of family planning in the health sector specially with its recognition as an essential element of primary health care at Alma Ata in $1978^{4}$. The family planning movement underwent a paradigm shift in September 1994 when the Programme of Action of the International Conference on Population and Development (ICPD) changed the focus of population programmes away from population numbers and family planning targets towards human development: the wellbeing of populations would thereafter be promoted by meeting their reproductive health needs over the life cycle with the emergence of a much wider approach rooted in gender and human rights ${ }^{5}$. It was explicitly noted in the Programme of Action of the ICPD that reproductive health includes sexual health, a convention that we adhere to in this article.

With the social sector being much emphasised in the Millennium Declaration, reproductive health was well represented in the three health MDGs 4, 5 and 6 through child and maternal mortality, access to reproductive health and HIV control ${ }^{6}$. Subsequent priorities for SDGs, as initially proposed by the High-Level Panel of the United Nations Secretary-General ${ }^{7}$, were considered by the intergovernmental Open Working Group ${ }^{8}$ which was set up at the 20-year follow-up of the Rio Conference on Sustainable 
Development. With the then prevailing concern for matters environmental, it is not surprising at all that social and economic components of sustainable development received less emphasis relatively and as a result, health is prominent in only the third SDG goal (SDG3). The reduction in the number of health goals has been fortunately accompanied by a concomitant increase in the attention paid to the broad dimensions of coverage and quality of health system besides the burden of cost on individuals, and through expansion at the target level. The SDG process has also explicitly recognized the interlinkages between different sectoral components, this response being due to the critique that the MDGs reinforced vertical silos and distorted competition for resources.

The broader context of the SDGs can be recognized in the multiple processes that have contributed their development and initial implementation. A wider range of intergovernmental processes has been mobilized to contribute to the realization of its expanded agenda. For example, the Paris Agreement adopted at the 21st Meeting of the Conference of Parties (COP 21) to the United Nations Framework Convention on Climate Change aims at strengthening the global response to the threat of climate change, in the context of sustainable development and efforts to eradicate poverty based on the principle of equity, common but differentiated responsibilities, and respective capabilities ${ }^{9}$.

An understanding of the monitoring process for the SDGs necessitates an appreciation of the preceding political declaration, a detailed consideration of relevant goals and their associated targets ${ }^{3}$. Whereas the main aspects pertaining to the clinical practice of reproductive health are largely addressed in the health sector, there are supporting statements from other sections such as gender and education: with the interdependence between the various goals, the operationalisation of strategies, including monitoring, should reflect those interlinkages. It is most appropriate that the attainment of universal access to reproductive health services, which is in line with the ICPD Programme of Action, the Beijing Platform for Action and their respective review processes, has also been included as a target under the Women's Empowerment goal (SDG5), referred thereafter as the gender goal.
Whilst the positioning of this target increases the priority accorded to reproductive health, including for linkages to SDGs beyond the health sector, there are related challenges for policy coordination, implementation and monitoring ${ }^{10,11}$.

\section{Policy formulation}

As SDGs were formulated around 2014 when both the Programme of Action of the ICPD and MDGs were coming to term, their legacy should be recognised for influencing policy dialogue and decision-making ${ }^{12}$. The ICPD was a testimonial to reproductive health in 1994 through its prominence especially for follow-up and advocacy. Whereas its indicators included details such as age at marriage, regarding the aim of discouraging child marriage, the incidence of other harmful practices and coverage of sexuality education, no substantial arrangements were made to strengthen local systems for related data collection. Its estimates of the resource requirements for demographic data were initially largely focused on census costs, supplemented by population surveys but estimates of resource requirements for both programmes and data needs were neither updated nor expanded until 2010.

International interventions for the implementation of MDGs focussed on a few health conditions for selected countries but a different approach will be used for SDGs which are much broader and universal, at least at this initial phase ${ }^{13,14}$. Whereas the MDGs were quite selective in their choice of indicators, they were not accompanied by specific arrangements for putting adequate data systems in place. However, in the last few years, the Independent Expert Review Group of the Commission on Information and Accountability for Women's and Children's Health initiated activities to strengthen monitoring and accountability. Other multistakeholder initiatives have also developed, tested and disseminated tools for improving monitoring of family planning and reproductive health outcomes $^{15,16}$. There has been substantial congruence among the various monitoring system, in part due to the participation of an overlapping set of institutions and individuals.

The preparatory activities for the SDGs included extensive consultations with interested parties and they provide a more coherent approach to development that will be much wider in the 


\section{Edouard \& Bernstein}

applicability than were the MDGs. In highincome countries, SDGs should be useful for equity by addressing disparities that reflect marginalised groups whether pertaining to geography, ethnicity, age or income. A fundamental principle of the SDGs, devised to address the perceived shortcomings of the MDGs, is to ensure that "no one is left behind". This approach was understood to remedy a reliance on national averages in the MDG monitoring system which would allow substantial progress to be reported even when underserved groups continued to lag behind their more privileged compatriots. The SDGs additionally seek to provide a common framework for evaluating development in all countries whereas the MDGs were largely focussed on addressing poverty in the poorest countries. Accordingly, the 2014 report of the Open Working Group ${ }^{8}$ had 17 goals and 126 targets: a significant expansion of the MDG ambit. While only one goal was devoted to health, it had 9 targets which significantly expanded the MDG focus and increased the priority on health system strengthening besides coverage of particular conditions.

\section{Targets}

The 2030 Agenda for Sustainable Development was approved at the United Nations Summit, of September 2015, as submitted ${ }^{3}$. The extended process of discussion that preceded the formal approval had been "short-circuited" earlier. The political compromises that had been required kept the original suggestions of the Open Working Group largely unchanged. Despite the widely shared understanding that there were too many and sometimes complex targets ${ }^{17}$, their modifications would have hindered progress by reopening the entire debate.

The health goal (SDG3) aims to "Ensure healthy lives and promote well-being for all at all ages ". Four of its 9 targets are specially directed towards reproductive health and they are all definitely legacies from the MDGs.

Target 3.1 "By 2030, reduce the global maternal mortality ratio to less than 70 per 100,000 live births"

There was much success in MDG5 with reductions in maternal mortality during the last five years:
Measurement for Sustainable Development Goals

further improvements can be expected due to the continuing impact of interventions ${ }^{18,19}$.

Target 3.2 "By 2030, end preventable deaths of newborns and children under 5 years of age, with all countries aiming to reduce neonatal mortality to at least as low as 12 per 1,000 live births and under-5 mortality to at least as low as 25 per 1,000 live births"

Whereas there have been substantial falls in infant and child mortality, the more resistant causes during the neonatal period are now receiving more emphasis $^{19,20}$.

Target 3.3 "By 2030, end the epidemics of AIDS, tuberculosis, malaria and neglected tropical diseases and combat hepatitis, waterborne diseases and other communicable diseases"

The control of HIV, and other communicable diseases, is a priority of the African Union ${ }^{21}$. HIV/AIDS is primarily sexually transmitted in most settings and in the MDGs, it was separated from other components of the continuum of care for sexual and reproductive health under a separate goal. The SDG formulation keeps it in a different target from other sexual concerns, albeit more ambitious than the corresponding MDG target by calling for the end, as opposed to mere diminution or control, of this HIV pandemic besides expanding the range of specific communicable diseases to be addressed and adding neglected tropical diseases.

Target 3.7 "By 2030, ensure
universal access to sexual and
reproductive health-care services,
including for family planning,
information and education, and the
integration of reproductive health into
national strategies and programmes"

Whereas the issue of universal access to reproductive health services did not make it in the initial list of targets of MDGs, it was a valuable addition $^{6,22}$ which officially took effect in 2008 and has now been confirmed in its inclusion for the SDGs ${ }^{23}$.

Four of the other 5 health targets are of significant relevance to reproductive health and 
they address issues and perspectives neglected in the MDGs. The fourth target calls for reduction of premature deaths from non-communicable diseases, which recognizes the ongoing epidemiological transition associated with ageing populations, and promotes mental health and wellbeing. Suicide is now the second greatest cause of death among adolescent girls, a fact reflecting social vulnerabilities at a time of sexual maturation and transition. The prevention of substance abuse, including narcotics and alcohol, comprises the fifth target. Alcohol consumption deserves attention in its own right, and especially as it is a factor in both consensual and nonconsensual sexual contact. The ninth target addresses adverse impact on reproductive health due to hazardous chemicals besides air and water pollution as well as soil contamination.

\section{Target 3.8 "Achieve universal health coverage, including financial risk protection, access to quality essential health-care services and access to safe, effective, quality and affordable essential medicines and vaccines for all"}

The issue of universal health coverage (Target 3.8) has been extensively discussed over the last three years $^{24,25}$ and has the potential to contribute substantially towards universal access to reproductive health services provided that a rightsbased approach supersedes so-called morality and sociocultural issues ${ }^{26,27}$. The selection of indictors for this target is still in process and will likely not be resolved until late 2016. When consensus is reached, the selections will be presented to the meeting of the United Nations Statistical Division in 2017.

The Women's Empowerment Goal (SDG5) aims to: "Achieve gender equality and empower all women and girls". The six targets under this goal address a wide range of issues regarding inequities and inequalities related to gender discrimination. The broad coverage expands the MDG emphasis on schooling, non-agricultural work and parliamentary participation with gender inequality related to particular sectors, such as education, being addressed under other relevant goals. It is most regrettable that a programmatic recommendation advancing comprehensive sexuality education was not accepted, along with other curriculum recommendations advanced by diverse groups of educators, during the negotiation process. However, all indicators are expected to be reported with disaggregation by sex: this approach will facilitate the identification of inequalities and inequities specially many of the key pillars of gender empowerment as proposed by the Gender Thematic Group of the UN Millennium Project ${ }^{28}$ and advanced by a broad range of civil society organizations.

Target 5.6 "Ensure universal access to sexual and reproductive health and reproductive rights as agreed in accordance with the Programme of Action of the International Conference on Population and Development and the Beijing Platform for Action and the outcome documents of their review conferences."

As the revision of MDGs of 2007, and operational in January 2008, was dictated by political considerations of the time, the target on access to sexual and reproductive health services was added within the health goal dedicated to maternal health ${ }^{6}$ : aspects of sexual and reproductive health not related to maternity were therefore implicitly excluded but most policy and programme attention emphasized the broader ICPD agenda ${ }^{5}$. It is therefore fortunate that the SDG solution to the broad and differentiated set of concerns related to sex and reproduction was to incorporate sexual and reproductive health services under the health goal SDG3 and the more non-clinical elements under gender goal SDG5.

Other targets under the gender goal SDG5 also explicitly address issues addressed in the Programme of Action of the ICPD. Target 1 generically opposes all forms of discrimination against women, placing the goal firmly in a human rights context. Target 2 calls for the elimination of all forms of violence against women and girls in public and private spheres, including trafficking and sexual and other kinds of exploitation: this points to responsibility for service providers and others to identify and address observed signs of violence. Target 3 calls for elimination of harmful practices, including child, early and forced marriage and female genital mutilation. In addition, the fourth and fifth targets address other concerns addressed in the Programme of Action of 
the ICPD but less directly related to health issues: valuing women's and girls' unpaid care and domestic work with the latter of which serving, even when paid, as a source of sexual exploitation addressed in the second target, and women's participation and leadership opportunities at all levels of decision making in political, economic and public life.

The scope and limits of Target 5.6, on universal access to sexual and reproductive health, will depend on the indicators finally selected for global monitoring, as discussed below, but also on the selection of indicators through regional and national processes. Some of these could relate to the role of women for decision making within households, beyond marriage and protection from abuse. These could include information on intrafamily assistance in medical access and on recognition and support for male reproductive health and men's support for their partners.

\section{Indicators}

The follow-up and review of the goals and targets will draw upon a set of global indicators complemented by additional indicators at not only regional but also national levels. It is expected that being valuable for decision-making, indicators will be used in high-level political fora. Whereas data will be largely retrieved from existing reporting systems, it is recognised that capacity strengthening will be needed in certain countries to ensure the timely availability of quality data that should be accessible in a disaggregated form.

Constituted of chief statistical officers from various countries, the Inter Agency and Expert Group on SDG Indicators (IAEG-SDG) is supplemented by inputs from technical agencies and responses from a diverse group of stakeholders prioritizing their concerns. It developed the global indicator framework, for approval by the UN Statistical Commission before adoption by the Economic and Social Council and the General Assembly of the United Nations as detailed below. This simple, and yet robust, framework addresses both the substance of the targets and of their means of implementation through necessary conditions for action and monitoring. For example, the means of implementation related to the gender goal relate to policy frameworks recognizing women's right to economic resources, access to communications technology for women's decisions and systems to track public resource commitments allocated to women's equality. It is recognized that certain preparatory tasks will be undertaken for establishing baseline data, where unavailable, once the indicators are finalized.

By May 2016, indicators for the targets had been proposed and evaluated by the Statistical Division. Several rounds of consultation have been facilitated and the IAEG-SDG has met three times. Indicators have been characterized as being in one of three tiers. Tier 1 indicators have an established methodology and substantial coverage globally. Tier 2 indicators have an established methodology, including in multicountry survey programmes, but more limited data availability. Tier 3 indicators have neither a consensus methodology nor, accordingly, existing databases. Continuing consultations are aiming to finalise the nature of indicators through the examination of available resources and the assessment of national and regional resources for their measurement. It is anticipated that Tier 1 indicators will form the backbone of the global monitoring whereas Tier 2 indicators will be monitored and work plans advanced for expanding coverage. Tier 3 indicators will remain under development and trial with the expectation that a refined set of measures will be presented for approval to the United Nations Statistical Commission at its meeting in 2017. Beyond the global indicator set, regional consultations will continue, as will national formulation of priorities for action and monitoring. It should be noted that a working group within the IAEG-SDG has been given the task to address the interlinkages among various goals and targets.

The targets most directly relevant to reproductive, maternal, newborn, child and adolescent health have been given health indicators whereas discussions continue for the development of indicators pertaining to sexual and reproductive health and rights under the gender goal.

The health target directly addressing sexual and reproductive health and rights concerns builds on the MDG framework as set out in the Table below for Target 3.7. Target 3.3, for HIV/AIDS, also included in the Table, uses new infections as its indicator, consistent with the aim of ending the epidemic. As already noted, Target 3.7 focuses on 
services and on the continuing integration of reproductive health into strategies and programmes. Unlike Target 5.B of the MDGs which maintained independent measures of met and unmet demand, the monitored indicator combines elements of contraceptive prevalence and unmet need for family planning into a single indicator that prioritizes the degree to which the health system satisfies the fertility preferences of reproductive age women with provision of the most effective family planning methods (with the implicit expectation that demand generation, i.e., lower fertility preferences, will result from progress on education, mortality reduction and other targets). As the overwhelming majority of contraceptive use is through modern methods in most countries ${ }^{29}$, this adjustment recognizes both the need for health systems to enable realization of expressed fertility desires, which is a rights-based concern, and the importance of effective, acceptable and affordable services of quality. It is noteworthy that the political sensitivities favouring the inclusion of traditional contraceptive methods did not prevail and only modern methods of contraception will be measured for this indicator. Additionally, the adolescent birth rate has been expanded to acknowledge sexual activity among younger adolescents by including the group of 1014 year olds: this approach will require both an adjustment of the sampling frames for reproductive age and new specialized surveys.

Efforts to ensure and monitor universal health coverage, as set out for Target 3.8 in the Table below, remains a work in progress. Significant progress has been made to identify a set of tracer interventions for indicator 3.8.1 across a cluster of (a) reproductive, maternal and child health interventions, (b) non-communicable disease interventions, (c) management of infectious diseases with antiretroviral therapy and treatment of tuberculosis, (d) service capacity and (e) access measures ${ }^{30}$. Whilst met demand for family planning is included in the composite indicator, as are other measures related to the continuum of care for reproductive, maternal, child and adolescent health, the measure seeks to capture overall health system strength and coverage: whereas the methodology exists, the limited availability of data led to indicator 3.8.1 being classified as Tier 2 while development work proceeds. Indicator 3.8.2 is less advanced due to divergent views on the emphasis to be placed on out-of-pocket outlays: whereas chief statistical officers in the IAEG-SDG proposed the proportion of the population either covered by health insurance or with access to public health services, civil society organizations objected and the current discussion seeks a compromise to address issues related to substantial out-of-pocket expenditures.

The elements of the gender goal pertaining to sexual and reproductive health and rights, as set out for Target 5.6 in the Table below, remain under development. The recent meeting of the IAEG-SDG upgraded indicator 5.6.1, on decisionmaking by women, from Tier 3 (no methodology; no data) to Tier 2 (methodology and limited data) after presentation of evidence about the availability of appropriate measures in the Demographic and Health Surveys. Further field tests of improved methodologies are underway. Indicator 5.6.2, regarding government policies, remains classified as a Tier 3 indicator and the methodology is not expected to be finalized before 2017.

\section{Operationalisation}

As the implementation of SDGs will be largely dependent on national processes, it is imperative for lobbies to be involved for various activities at the grassroots level ${ }^{31,32}$. Emphasis is needed on models for working together, whether through the United Nations system or platforms for interactions with NGOs, to ensure intersectoral activities at all levels and widespread buy-in and participation by a range of national stakeholders $^{33,34}$. The health status of peoples and populations will improve from direct service delivery with related macrointerventions and microinterventions as opposed to political statements at high-level jamborees. However, these latter activities could help for the mobilisation of resources and their judicious use through good governance with interventions for 15 years, national governments being in control.

Besides a legitimate controversy on the relevance of goals, formulation of targets and selection of indicators, there will be a continuing debate on reproductive health issues such as financing, human rights and the comparative role 
Table1: Sexual and Reproductive Health Targets and Indicators, as of May 2016

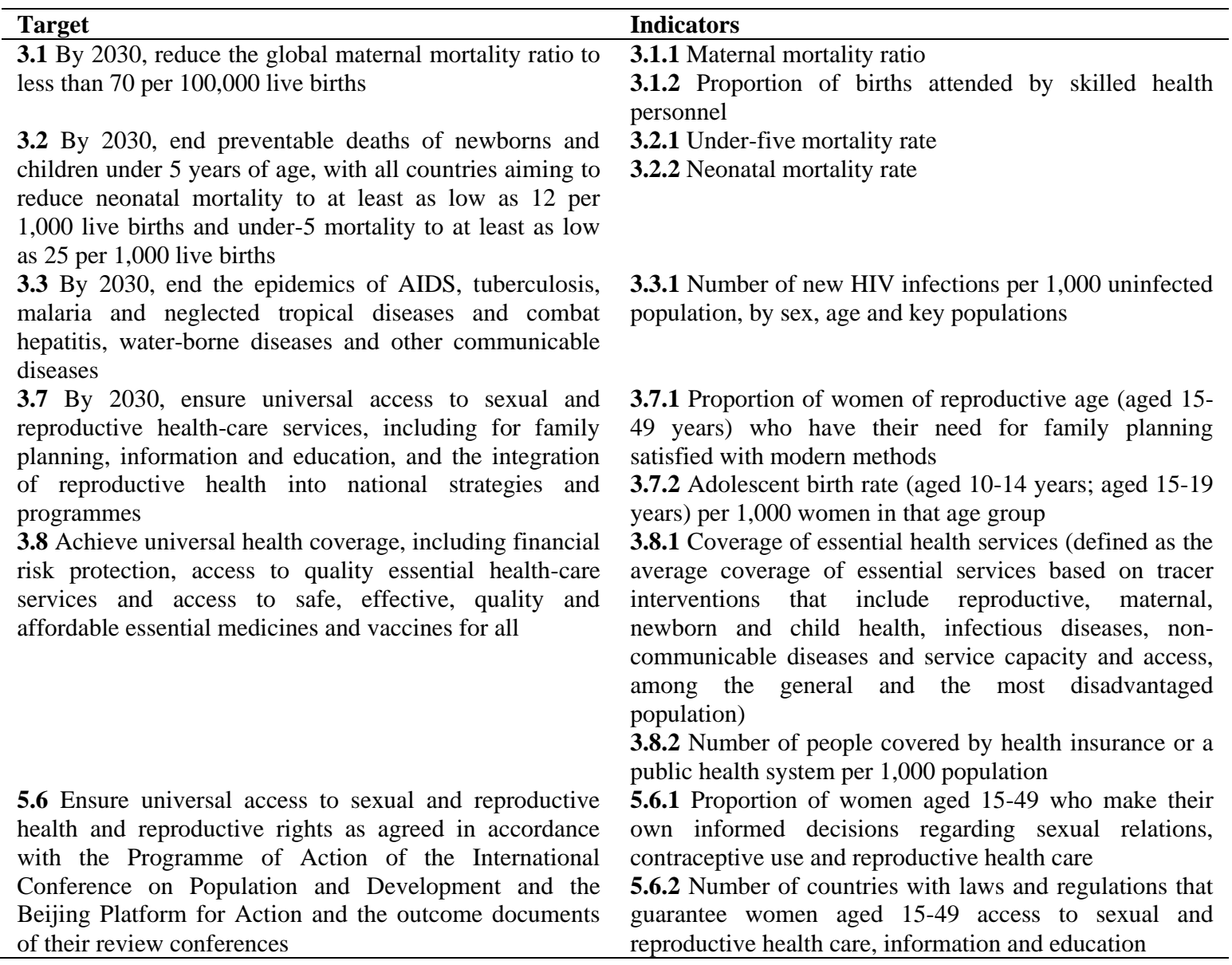

of prevention as opposed to curative services. A challenge will be the integration of those latter issues in the monitoring process by providing hard data for objective decision-making in the context of an evidence-based approach that includes identification of local gaps in services and missed opportunities for synergies and referrals. The issue of human rights is specially relevant for reproductive health services and should be addressed by some indicators.

Lessons can be learned from the operationalization of the MDGs relating to reproductive health over the past decade. After the adoption of the new target on reproductive health in $2007^{6}$, a large number of global, regional and national partnerships advanced reproductive health writ large by adding family planning to traditional maternal and child health concerns so as to take advantage of the political decision ${ }^{35}$. Each of these efforts, often involving a common core of institutions and individuals, established databases and advanced operational linkages among global, regional and national participants. Efforts have included the development of indicator sets, data collection and processing, dissemination methodologies, protocols, strategies for intensive national level consultations and resource mobilisation. Pilots and applications have improved the reliability, quality and timeliness of data collection and use. Those activities are supported by various mechanisms including funding from the Global Financing Facility that was recently set $u^{36}$. These initiatives are, in various ways, explicitly considering issues pertaining to rights for both programmatic efforts and protection of privacy of individuals, with special concern for vulnerable and marginalized populations. This proliferation of policy dialogues, technical reviews and methodological advances mirrors the development of efforts advancing progress on HIV/AIDS in the years following its inclusion in the initial MDGs as part of an 
integrated approach to reproductive health ${ }^{37}$.

Notwithstanding this accelerating progress, a major limitation for the validity of indicators remains, resulting from remaining levels of inaccurate data as collected at the grassroots level ${ }^{38}$ : any problem faced there would be compounded at higher levels of data aggregation. Much can be and has been learned from the success of immunisation and malaria programmes with the implementation, by national governments, of core sets of coverage indicators with standardised methods for their measurements through international coordination mechanisms ${ }^{39}$.

It is increasingly recognized that indicators should span the range of interventions from national policies, through process procedures and quality standards, to outputs besides outcomes for impact. Coverage over the continuum of care ${ }^{40,41}$ will need to be monitored besides the incidence of and follow-up for referrals, complications and side-effects as well as responses to them.

Unfortunately, indicators can sometimes distort government priorities when resources focus on interventions that will impact on indicators as opposed to other aspects of the targets and the supportive conditions required and barriers to be overcome. Decision makers should be aware that the SDGs and their targets are interdependent and indivisible: indicators are merely proxies to measure progress. As different regions and, more critically, nations have different sensitivities about sexual and reproductive health concerns, care must be taken to maintain a holistic perspective $\mathrm{e}^{42,43}$. As a cautionary example, the emerging global universal health care monitoring effort takes a broad perspective in the diverse areas of reproductive, maternal, neonatal, child and adolescent health ${ }^{44,45}$ but care should be taken for family planning, being part of clinical practice, to feature among its set of health interventions as opposed to being grouped elsewhere due to its linkages with other social conditions ${ }^{46}$. National commitment to a common holistic approach will be essential for accountability and programmatic corrections. Neither these sensitivities nor data scarcity should prevent countries from making every practical effort to cover all components of sexual and reproductive health. It should be noted that when comprehensive knowledge of HIV/AIDS methods of transmission and protection was accepted as an MDG indicator in 2001, data were available for only 39 countries whereas it is now nearly universal.

Whereas SDGs have a 15 -year horizon, a major long-term challenge will consist of the shifting roles and relationships through the life course regarding changes in the age structure of populations specially for intergenerational relations: this is in sharp contrast with MDGs which had too much of an individual focus due to the traditional viewpoint of demography and epidemiology whereby populations are broken down by age and sex rather uniting individuals through associations of cross-gender and crossage. Beyond aggregate statistics, monitoring systems should allow examination of the interdependency of choices by health services and by individuals along the way to full coverage, beyond the defined framework of universal health coverage, of health needs ${ }^{47}$.

According to the SDG discourse, targets are aspirational and global but with the accepted multilateral principle of national sovereignty, governments can determine national targets that are appropriate for local circumstances. With their limited finite resources, national governments must be highly selective for their introduction of additional indicators as opposed to the unfortunate all-in approach whereby all seemingly reasonable suggestions are adopted without due consideration to resource limitations that would affect implementation. Moreover, governments should prioritise their international commitments for the timely reporting for international indicators ${ }^{48,49}$, whether at the global or regional level, before the introduction of any additional indicators whether at national or subnational level.

Finally, it is imperative to promote open data policies for public access to official datasets, whether national, regional or global, not simply for transparency purposes. It is most important to ensure the exploitation of those valuable resources both to improve the availability of objective information as part of the evidence base for decision-making and to promote academic research with its potential for contributing to the health literature.

\section{Contribution of Authors}

Both authors conceived and designed the structure of this review article besides preparing and approving the manuscript. 


\section{References}

1. United Nations. Road map towards the implementation of the United Nations Millennium Declaration. Document A/56/326. Report of the SecretaryGeneral. New York: United Nations, 2001.

2. United Nations. Millennium Development Goals Report 2015. New York: United Nations, 2015.

3. United Nations. Transforming our world: the 2030 agenda for sustainable development. Resolution adopted by the General Assembly on 25 September 2015. Document A/RES/70/1. New York: United Nations, 2015.

4. Gish O. Selective primary health care: old wine in new bottles. Soc Sci Med 1982;16:1049-1054.

5. United Nations. Key actions for the further implementation of the Programme of Action of the International Conference on Population and Development adopted by the twenty-first special session of the General Assembly, New York, 30 June to 2 July 1999. Paragraphs 44 and 52. New York: United Nations, 1999.

6. Bernstein S, Edouard L. Targeting access to reproductive health: giving contraception more prominence and using indicators to monitor progress. Reprod Health Matters 2007;15:186-191.

7. United Nations. A new global partnership: eradicate poverty and transform economies though sustainable development. Report of the High-Level Panel of Eminent Persons on the Post-2015 Development Agenda. New York: United Nations, 2013.

8. United Nations. Report of the Open Working Group of the General Assembly on Sustainable Development Goals. Document A/68/970. New York: United Nations, 2014.

9. Horton R. Australia leads on climate and health. Lancet 2015;386:1520.

10. Gostin LO, Friedman EA. The Sustainable Development Goals: one-health in the world's development agenda. JAMA 2015;314:2621-2622.

11. Magar V. Gender, health and the Sustainable Development Goals. Bull World Health Organ 2015;93:743.

12. Simkiss D. The Millennium Development Goals are dead; long live the Sustainable Development Goals. J Trop Pediatr 2015;61:235-237.

13. Murray CJ. Shifting to Sustainable Development Goals implications for global health. $\mathrm{N}$ Engl $\mathrm{J}$ Med 2015;373:1390-1393.

14. Sachs JD. High stakes at the UN on the Sustainable \ Development Goals. Lancet 2013;382:1001-1002.

15. Crofts J, Moyo J, Ndebele W, Mhlanga S, Draycott T, Sibanda T. Adaptation and implementation of local maternity dashboards in a Zimbabwean hospital to drive clinical improvement. Bull World Health Organ 2014;92:146-152.

16. Brown W, Druce N, Bunting J et al. Developing the " 120 by 20 " goal for the global FP2020 initiative. Stud Fam Plann 2014;45:73-84.

17. Horton R. Why the Sustainable Development Goals will fail. Lancet 2014;383:2196.
18. Edouard L, Bernstein S. Sexual and reproductive health at 2015 and beyond: a global perspective. J Obstet Gynaecol Can 2015;37:872-879.

19. World Health Organization. Monitoring of the achievement of the health-related Millennium Development Goals. Sixty-ninth World Health Assembly. Document A69/14. Geneva: World Health Organization, 2016.

20. World Health Organization. Health in 2015: from MDGs, Millennium Development Goals to SDGs, Sustainable Development Goals. Geneva: World Health Organization, 2015.

21. African Union. Agenda 2063: the Africa we want. Addis Ababa, Ethiopia: African Union, 2016.

22. Edouard L, Bernstein S. Progress towards the Millennium Development Goals: a long trek for reproductive health. J Obstet Gynaecol Can 2009;31:945-955.

23. World Health Organization. Health in the 2030 agenda for sustainable development. Sixty-ninth World Health Assembly. Document A69/15. Geneva: World Health Organization, 2016.

24. Brolan CE, Hill PS. Universal health coverage's evolving location in the post-2015 development agenda: key informant perspectives within multilateral and related agencies during the first phase of post-2015 negotiations. Health Policy Plan 2016;31:514-526.

25. Sobel HL, Huntington D, Temmerman M. Quality at the centre of universal health coverage. Health Policy Plan 2016;31:547-9.

26. Edouard L. Of contraception and morality. J Fam Plann Reprod Health Care 2007;33:283-284.

27. Forman L, Ooms G, Brolan CE. Rights language in the sustainable development agenda: has right to health discourse and norms shaped health goals? Int J Health Policy Manag 2015;4:799-804.

28. Task Force on Child Health and Maternal Health. Who's got the power? Transforming health systems for women and children. New York: United Nations Millennium Project, 2005.

29. United Nations. Trends in Contraceptive Use Worldwide 2015. Department of Economic and Social Affairs, Population Division. Document ST/ESA/SER.A 1349. New York: United Nations, 2015.

30. World Health Organization/World Bank. Tracking universal health coverage: First global monitoring report. Geneva, Switzerland: World Health Organization, 2015.

31. Jha A, Kickbusch I, Taylor P, Abbasi K. Accelerating achievement of the sustainable development goals. BMJ 2016;352:409.

32. Fluckiger Y, Seth N. Sustainable Development Goals: SDG indicators need crowdsourcing. Nature 2016;531:448.

33. Frost L, Hinton R, Pratt BA et al. Using multistakeholder dialogues to assess policies, programmes and progress for women's, children's and adolescents' health. Bull World Health Organ 2016;94:393-395.

34. Marston C, Hinton R, Kean S et al. Community participation for transformative action on women's, children's and adolescents' health. Bull World 


\section{Edouard \& Bernstein}

Health Organ 2016;94:376-382.

35. Every Woman Every Child. Saving lives, protecting futures: progress report on the Global Strategy for Women's and Children's Health 2010-2015. New York: United Nations, 2015.

36. Jacovella D, Evans TG, Claeson M, Kagia R, PablosMendez A. Global Financing Facility: where will the funds come from? Lancet 2016;387:121-122.

37. Chukwujekwu O, Chabikuli NO, Merrigan M, Awi D, Hamelmann C. Integrating reproductive health and HIV indicators into the Nigerian health system building an evidence base for action. Afr J Reprod Health 2010;14:109-116.

38. Sustainable Development Solutions Network. Indicators and a monitoring framework for the Sustainable Development Goals: launching a data revolution for the SDGs. A report to the Secretary-General of the United Nations by the Leadership Council. New York: Sustainable Development Solutions Network, 2015:77-79.

39. Grove J, Claeson M, Bryce et al. Maternal, newborn, and child health and the Sustainable Development Goals - a call for sustained and improved measurement. Lancet 2015;386:1511-1514.

40. Edouard L. Bernstein S. Seeking equity in maternal health. Lancet 2006;367:279-281.

41. Bernstein S, Say L, Chowdhury S. Sexual and reproductive health: completing the continuum Lancet 2008;371:1225-1226.

42. Bernstein S. Parliamentarian resource kit on SRHR and population and development - links in Asia and the Pacific in the post 2015. ( $2^{\text {nd }}$ edition $)$ Bangkok:

\section{Measurement for Sustainable Development Goals}

Asian Forum of Parliamentarians on Population and Development, 2016.

43. Ahmed SM, Rawal LB, Chowdhury SA et al. Crosscountry analysis of strategies for achieving progress towards global goals for women's and children's health. Bull World Health Organ 2016;94:351-361.

44. Kuruvilla S, Bustreo F, Kuo T et al. The Global Strategy for Women's, Children's and Adolescents' Health (2016-2030): a roadmap based on evidence and country experiences. Bull World Health Organ 2016;94:398-400.

45. Victora CG, Requejo JH, Barros AJD et al. Countdown to 2015: a decade of tracking progress for maternal, newborn, and child survival. Lancet 2016;387:2049 -2059 .

46. Wagstaff A, Dmytraczenko T, Almeida G et al.

Assessing Latin America's progress toward achieving universal health coverage. Health Affairs 2015;34:1704-1712.

47. Brende B, Hoie B. Towards evidence-based, quantitative Sustainable Development Goals for 2030. Lancet 2015;385:206-208

48. World Health Organization. Towards a monitoring framework with targets and indicators for the health goals of the post-2015 Sustainable Development Goals. Geneva: World Health Organization, 2015.

49. World Health Organization. Operational plan to take forward the Global Strategy for Women's, Children's and Adolescents' Health: committing to implementation. Sixty-ninth World Health Assembly. Document A69/16. Geneva: World Health Organization, 2016. 